ANNE LENQUETTE, Les romans D'Álvaro Pombo. Savoir et fiction en EsPagne (xX ET XX $X^{E}$ SIÈCLES), PARÍs, HONORÉ CHAMPION, 2016, 377 PP.

\title{
CRISTINA OÑORO
}

Universidad Complutense de Madrid

La prestigiosa editorial francesa Honoré Champion -con más de ciento treinta años de historia a sus espaldas editando textos académicos de referencia internacional- ha publicado recientemente Les romans d'Álvaro Pombo. Savoir et fiction en Espagne ( $\mathrm{XX}^{E}$ et $\mathrm{XX}^{\mathrm{E}}$ siècles), un título que, sin lugar a dudas, marca un antes $y$ un después en los estudios críticos sobre el célebre escritor español nacido en Santander en 1939. La autora de esta primera monografía en francés sobre Álvaro Pombo es Anne Lenquette, catedrática de literatura española en la Université de Limoges e investigadora del grupo E.H.I.C. (Espaces Humains et Interactions Culturelles) de dicha universidad, quien, durante las últimas dos décadas, ha consagrado el grueso de su investigación a la narrativa hispánica contemporánea.
El cuidado volumen de casi cuatrocientas páginas aparece introducido por Geneviève Champeau, una de las figuras de referencia del hispanismo francés. Desde las primeras líneas de su prólogo, subraya Champeau el carácter pionero de esta monografía, pues el estudio de Anne Lenquette tiene el valor de recorrer un camino poco explorado hasta este momento en Francia; y es que, como la propia autora apunta al comienzo del libro, Álvaro Pombo es un narrador relativamente poco estudiado todavía fuera de las fronteras de nuestro país. En este sentido, el volumen que aquí nos concierne constituye una pieza fundamental en la construcción del aparato crítico sobre la obra de Pombo $\mathrm{y}$, con seguridad, servirá no solo para dar a conocer al escritor en nuestro país vecino sino también como acicate para futuros trabajos sobre su universo literario. 
Como explicita el subtítulo del volumen, el hilo conductor que guía a Lenquette en su trabajo -y que problematiza cada concepto, obra o idea analizada- es la relación que se establece entre conocimiento y ficción en la poética pombiana. «Quelles sont les caractéristiques des fictions d'Á. Pombo ? Par quels biais propres sont-elles porteuses de verité ?» (p. 20), se pregunta la autora en el capítulo introductorio. Interrogantes que, en definitiva, pueden resumirse en una única pregunta: ¿cuál es la «la poética del saber» que construye Pombo en sus creaciones literarias? Las coordenadas teóricas en las que podemos inscribir estos interrogantes no son otras que las establecidas en las décadas de los años sesenta y setenta por el pensamiento francés de corte post-estructuralista. Me refiero a las obras seminales de Michel Foucault (L'archéologie du savoir, 1969) y François Lyotard (La condition postmoderne, 1979) que, hace ya medio siglo, dibujaron un escenario nuevo para el pensamiento contemporáneo. Nuestra monografía, en definitiva, se sitúa en ese espacio epistemológico posmoderno en el que las prácticas discursivas -también las ficciones literarias- y su relación con el saber se vuelven problemáticas. Un espacio epistemológico de «duda activa», en palabras de Lenquette, que, me atrevería a decir, es el que le va como anillo al dedo al quehacer literario de Pombo, pues no en vano él mismo posee formación filosófica, lo que continuamente se refleja en sus novelas a través de conceptos y referentes fundamentales -de Sócrates a Hegel- de la tradición filosófica occidental.
Sin abandonar nunca la pregunta de raíz filosófica por la «poética del saber», Anne Lenquette se adentra con paso firme en el conjunto de la producción narrativa de Pombo publicada hasta 2012. Estructurada en tres grandes partes, la monografía combina la aproximación panorámica y el estudio pormenorizado -incluso retórico- en un movimiento crítico continuo que va del detalle filológico al marco general, del ejemplo escogido con inteligencia al comentario interpretativo de largo recorrido. Se trata, en otras palabras, de un trabajo en el que convergen la paciencia del estudioso erudito y la audacia del intérprete con vocación filosófica. Esta naturaleza híbrida del libro lo hace interesante tanto para estudiosos de la literatura como para filósofos, sin menoscabo del lector poco familiarizado con la obra de Pombo que pueda emplear este libro precisamente como guía de iniciación a la misma. Por otro lado, cabe destacar que la importancia concedida por Lenquette a las narrativas del «yo» (del diario íntimo a la autoficción) en la poética pombiana acerca este trabajo a otras investigaciones que actualmente están en marcha dado el desarrollo que han tenido dichos géneros literarios en la narrativa hispánica última.

El corpus de nuestro estudio es muy amplio, pues incluye las dos grandes etapas que tanto la crítica como el autor convienen en señalar como esenciales en la trayectoria novelesca pombiana. Como resume Lenquette (p. 18), la primera etapa incluiría sus cuatro primeras obras El parecido (1979), El héroe de las mansardas de 
Mansard (1983), El hijo adoptivo (1984) y Los delitos insignificantes (1986), y la segunda el resto de sus obras aparecidas antes de 2012, es decir, El metro de platino iridiado (1990), Aparición del eterno femenino (1993), Telepena de Celia Cecilia Villalobo (1995), Donde las mujeres (1996), La cuadratura del círculo (1999), El cielo raso (2001), Una ventana al norte (2004), Contra natura (2005), La fortuna de Matilda Turpin (2006), Virginia o el interior del mundo (2009) y La previa muerte del lugarteniente Aloof (2009).

Además de las obras publicadas en los últimos años (El temblor del héroe, 2012, Quédate con nosotros, Señor, porque atardece, 2013, y La transformación de Johanna Sansíleri, 2014), Lenquette solo dejaría fuera de su análisis las novelas históricas, como El cielo raso o Una ventana al norte, pues, a su modo de ver, en ellas tiene demasiado peso el referente histórico, lo que exigiría un análisis de otras características.

Las dos primeras partes de la monografía, tituladas respectivamente «Visages et masques du réel dans la fiction pombienne» $\mathrm{y}$ «De l'autre côté du miroir: faux-semblants de la parole et dérobade du moi», se construyen de forma orgánica y complementaria. En la primera, Anne Lenquette aborda la nada sencilla tarea de acercarse a los conceptos de «realidad», «irrealidad», «verdad» $\mathrm{y}$ «mentira» en la poética pombiana. Para ello presta especial atención a figuras recurrentes en el universo del autor, como el fantasma o el doble, así como a los juegos textuales de carácter caleidoscópico y polimórfico con las instancias narrativas. Pero también a los vínculos que, en sus obras, Pombo establece entre lo «irreal» y lo no-normativo o lo extraño. Así, como subraya Lenquette, en la obra de dicho autor se despliega un juego constante entre «le visible et l'invisible qui souligne la difficulté de distinguer de façon infaillible les contours fuyants de la réalité et introduit une subtile réflexion philosophique sur la nature insaisissable de celle-ci» (p. 44). Un juego que, para la autora, conduce a la conclusión de que en la obra de Pombo «Il existe donc autant de réalités que d'êtres humaines et de points de vue» (p. 81).

Como decía, Lenquette no abandona nunca durante su estudio la pregunta por la «poética del saber», lo que en esta primera parte se evidencia en el título del último epígrafe («Le statut de la fiction littéraire»), que pone el broche al incidir en que todos estos dispositivos pombianos estudiados, tanto formales como temáticos, están al servicio de una reflexión más amplia sobre la naturaleza de la ficción naturaleza ontológica y epistemológica- y sus vínculos con la verdad.

La segunda parte («De l'autre côté du miroir: faux-semblants de la parole et dérobade du moi») desplaza la mirada hacia las palabras y la lengua. Así, si en la primera parte la naturaleza de la ficción era interrogada desde un enfoque ontológico y epistemológico, aquí Lenquette concentra sus esfuerzos es tratar de entender cómo operan las palabras en la construcción del saber y la verdad en la poética pombiana, deslizándose hacia una perspectiva más cercana a las ciencias del lenguaje. Es 
en esta parte en la que, precisamente, cobra radical importancia la conexión entre palabra e identidad, discurso y construcción de sí mismo, cuestiones que se hallan todas ellas en el corazón de los actuales estudios sobre narrativas del yo.

La tercera parte ( «L'ambition herméneutique et cognitive du littéraire») está dedicada a los diferentes mecanismos de interferencia sintáctica, sonora y semántica que ponen en juego las ficciones pombianas en su esfuerzo por no ofrecer al lector un único sentido de forma transparente. Asimismo, en el último capítulo, se revisan algunas de las referencias intertextuales fundamentales (Hegel, Elena Fortún, Emilia Pardo Bazán) que habitan el universo del autor y que, a su manera, también constituyen «mediaciones de sentido». Como explicita el propio título de estos capítulos finales, narrador y lector son tratados como hermeneutas, buscadores de sentido, intérpretes que construyen saber y verdad a través de lo literario, lo que vuelve a incidir en esa «poética del saber» sobre la que se interroga Lenquette a lo largo de todo el libro. Finalmente, en las últimas páginas de la monografía, Lenquette acabará concluyendo que «À la complexité du réel l'auteur oppose une approche de la connaissance fondée sur le refus d'une conception figée du savoir» (p. 324).

Acompaña a la monografía un extensa bibliografía y dos índices, onomástico y de palabras clave, que serán de gran utilidad no solo a los lectores del libro sino a investigadores sobre la obra de Pombo. En la impresionante sección bibliográfica, cuidadosamente organizada, destaca la rigurosa revisión realizada por Lenquette de toda la obra crítica sobre Pombo así como la presencia de las principales obras de teoría literaria que, en el siglo $\mathrm{XX}$, se han interrogado sobre la ficción literaria, de M. Bajtín a Darío Villanueva, pasando por las obras fundamentales de los enfoques mimético, estructuralista, cognitivo, pragmático, estética de la recepción y un largo etcétera.

Como escribía al comienzo de esta reseña, Les romans d'Álvaro Pombo. Savoir et fiction en Espagne ( $\mathrm{xx}^{e}$ et $\mathrm{Xx}^{e}$ siècles) sin duda está llamada a convertirse en una obra de referencia internacional en los estudios sobre el autor santanderino. Cabe esperar que a esta publicación le sigan muchas otras dedicadas al estudio de uno de los principales novelistas españoles del cambio de siglo. 